\title{
Anaphylaxis at autopsy
}

\author{
Roger W. Byard ${ }^{1}$
}

Accepted: 8 July 2016/Published online: 29 August 2016

(C) Springer Science+Business Media New York 2016

"We can only say of him that his power to react has undergone a change" Clemens von Pirquet (1874-1929)

The concept of allergic reactions was first proposed by Clemens von Pirquet when he was a resident in pediatrics at the Universitäts KinderKlinic in Vienna. In 1906 he published a short two page paper in which he suggested that exposure to foreign material (antigens) alters the immune system of an individual, and that while subsequent exposure may induce immunity, it may also result in hypersensitivity or altered reactivity. He coined the term allergy from the Greek allos meaning "other" or "different," and ergon meaning "energy" or "work" [1, 2].

Although his work was recognized by the forensic community, cases of fatal anaphylaxis are still not commonly recorded in medicolegal practice despite increases in potentially life-threatening food allergies in the community over the past few years [3]. While it is difficult to determine the precise prevalence of food allergy because of the complex testing required, self-reported food allergies have increased by a factor of 1.5 from 2001 to 2010 in the United States. This is thought to be due to alterations in gut commensal microbiota induced by increasing amounts of antibiotics that are prescribed and that are present in certain foods in industrialized countries [4]. Systemic hypersensitivity reactions have been responsible for as many as one in 200 adult presentations to emergency departments [5], although recorded deaths from anaphylaxis remain rare (0.12-1.06 deaths per million person-years) [6]. However,

Roger W. Byard

roger.byard@sa.gov.au

1 School of Medicine, The University of Adelaide, Frome Road, Level 3 Medical School North Building, Adelaide 5005, SA, Australia the apparent increase in numbers of allergic reactions in the community raises the question as to why there has not been a concomitant increase in cases of anaphylactic sudden death being identified at the time of autopsy. Are the allergies that are on the increase in the community not potentially life-threatening, are they being more effectively treated, or are not all cases that result in rapid deterioration and death being identified? Possible reasons for the latter may involve reduced suspicions on the part of examining pathologists. This may be due to a number of factors including absence of a typical presenting history, the rapidity of some of these deaths, the non-specificity of macroscopic and microscopic autopsy findings, and lack of appropriate testing. The presence of potentially lethal underlying medical diseases such as stenosing coronary artery atherosclerosis in older individuals may also divert attention away from a condition that may have far more subtle manifestations [7].

Anaphylaxis refers to the cascade of events that may follow exposure to a particular antigen causing an acute multiorgan response, most often affecting the skin, respiratory, cardiovascular, and neurological systems. It has been defined as "a severe, life-threatening generalized or systemic hypersensitivity reaction" [8]. Usually mediated by immunoglobulin $\mathrm{E}$ (IgE), it represents a type I hypersensitivity reaction to a foreign material such as food (e.g., peanuts), medications (e.g., penicillin), or animal venom (e.g., wasp or bee stings). This causes release of chemical mediators from tissue mast cells and basophils. Classically it follows prior exposure to a particular allergen and results in flushing, angioedema, pruritis, hypotension, arrhythmias, shortness of breath, tachypnea, dysphagia, and reduced conscious state. These features result from smooth muscle spasm and increased vascular permeability. 
The term anaphylactoid reaction was once used for nonIgE-mediated reactions that involve $\operatorname{IgG}$ and immune complex complement [9], although the clinical significance of non-IgE-mediated anaphylaxis has been questioned [10]. It has been suggested that better terminology for this range of events would be allergic (IgE-mediated and non-IgEmediated), and nonallergic anaphylaxis (where mast cells and basophils degranulate without the actions of immunoglobulins [8].

An age-related vulnerability exists with an increase in food related allergies in the very young. One Australian study showed that more than $10 \%$ of 1 -year-old children had proven IgE-mediated allergies [11]. Children may, however, grow out of their allergies, with 70-80\% of children with reactions to milk or eggs being able to tolerate these foods by the age of 16 years. In contrast, only $20 \%$ of children with peanut allergies and $10 \%$ with tree nut allergies will outgrow them [4]. It has been suggested that the prevalence of allergic diseases is also increasing in the elderly, which in combination with significant comorbidities has increased the risk of fatal outcomes [12, 13].

There are a number of specific situations where the possibility of anaphylactic reactions should be considered in cases of sudden death. One example involves outdoor workers where there is the possibility of exposure to workrelated allergens. This may involve animal bites or insect stings. For example, deaths in snake handlers are more likely to be due to anaphylaxis rather than to the direct toxic effects of reptile venom [14]. Unfortunately insect stings or snake bites may be quite difficult to identify at autopsy and so may not be considered or carefully looked for in the absence of a history. Other usually less severe occupational exposures involve vegetable allergens, food products, and drugs [15]. Perioperative anaphylaxis should be thought of in deaths that occur around the time of surgery as it has been identified in $1 / 10,000$ of patients undergoing surgery, most often related to exposure to neuromuscular blockers [16].

Death from anaphylaxis usually results from a combination of factors including upper airway obstruction from mucosal edema, asphyxia from bronchospasm, and shock due to massive fluid shifts. Hemorrhagic and thromboembolic phenomena may also occur [7]. Symptoms develop quite quickly after exposure to a particular antigen (within $20 \mathrm{~min}$ ) in $86 \%$ of cases, with $33 \%$ of deaths occurring within $30 \mathrm{~min}$, and $50 \%$ within $1 \mathrm{~h}$ [17]. There are however numerous problems that arise in establishing the diagnosis of anaphylaxis at autopsy as it remains essentially a clinical diagnosis with features that may either have never developed, or not persisted until the time of postmortem examination. For example, skin changes are either very subtle or absent in as many as $20 \%$ of cases [18].
Ideally cutaneous swelling, upper airway edema, and hyperinflation of the lungs with mucus plugging may be observed. Airway swelling may be generalized or limited to the oropharynx, nasopharynx, epiglottis, larynx, or upper trachea, but it may also be absent [19]; e.g., no typical macroscopic features were present in $41 \%$ of cases at autopsy in one series attributed to the rapidity with which such deaths may occur [20]. Microscopic evaluation of upper airways may show edema with an infiltrate of eosinophils and immunohistochemical staining of tissue sections may reveal tryptase, a mast-cell-specific enzyme. While excluding other causes of death is always necessary, it is also very important not to confuse an illness or condition that somebody may simply have died with, with something that they may have actually died from.

Postmortem testing of sera is an extremely useful diagnostic step with elevated levels of allergen-specific IgE indicating antemortem sensitization, and a tryptase level of $10 \mu \mathrm{g} / \mathrm{l}$, or more, being a sensitive $(86 \%)$ and specific $(88 \%)$ marker. Other authors have taken a tryptase level of $>20 \mu \mathrm{g} / 1[21,22]$. It should be noted, however, that elevated tryptase levels have been found in deaths due to trauma, SIDS, and heroin overdose. This has resulted in the suggestion that perhaps some of these deaths have had an allergic component. Serum tryptase and IgE levels may also increase with increasing postmortem interval [22].

For a pathologist to suspect the possibility of fatal anaphylaxis there usually needs to be a history of exposure to an antigen, followed by shortness of breath and collapse, in a previously sensitized individual. Without these prompts the non-diagnostic findings at autopsy will continue to make this a problematic diagnosis. It is, therefore, possible, as with other subtle immunological, biochemical, and metabolic conditions, that not all cases will be identified at autopsy giving us a potentially skewed perception of the role that anaphylaxis may play in contemporary mortality.

\section{References}

1. Kay AB. 100 years of allergy: can von Pirquet's word be rescued? Clin Exp Allerg. 2006;36:555-9.

2. Igea JM. The history of the idea of allergy. Allergy. 2013;68:966-73.

3. Benedé S, Blázquez AB, Chiang D, Tordesillas L, Berin MC. The rise of food allergy: environmental factors and emerging treatments. EBiomed. 2016;7:27-34.

4. Iweala OI, Burks AW. Food allergy: our evolving understanding of its pathogenesis, prevention, and treatment. Curr Allergy Asthma Rep. 2016;16:37.

5. Brown SGA. Clinical features and severity grading of anaphylaxis. J Allergy Clin Immunol. 2004;114:371-6.

6. Belsey SL, Flanagan RJ. Postmortem biochemistry: current applications. J Forensic Leg Med. 2016;41:49-57. 
7. Riches KJ, Gillis D, James RA. An autopsy approach to bee sting-related deaths. Pathology. 2002;34:257-62.

8. Johansson SGO, Bieber T, Dahl R, Friedmann PS, Lanier BQ, Lockey RF, et al. Revised nomenclature for allergy for global use: report of the Nomenclature Review Committee of the World Allergy Organization, October 2003. J Allergy Clin Immunol. 2004;113:832-6.

9. Muñoz-Cano R, Picado C, Valero A, Bartra J. Mechanisms of anaphylaxis beyond IgE. J Invest Aller Clin Immunol. 2016;26:73-82.

10. Finkelman FD, Khodoun MV, Strait R. Human IgE-independent systemic anaphylaxis. J Allergy Clin Immunol. 2016;137:1674-80.

11. Osborne NJ, Koplin JJ, Martin PE, Gurrin LC, Lowe AJ, Matheson MC, et al. Prevalence of challenge-proven IgE-mediated food allergy using population-based sampling and predetermined challenge criteria in infants. J Allergy Clin Immunol. 2011;127:668-76.

12. González-de-Olano D, Lombardo C, González-Mancebo E. The difficult management of anaphylaxis in the elderly. Curr Opin Alergy Clin Immunol. 2016;16(4):352-60.

13. Byard RW. Frailty syndrome-medicolegal considerations. J Forensic Leg Med. 2015;30C:34-8.

14. Bury D, Langlois NEI, Byard RW. Animal-related fatalities Part II: characteristic autopsy findings and variable causes of death associated with envenomation, poisoning, anaphylaxis, asphyxiation and sepsis. J Forensic Sci. 2012;57:375-80.

15. Quirce S, Fiandor A. How should occupational anaphylaxis be investigated and managed? Curr Opin Aller Clin Immunol. 2016;16:86-92.

16. Chen X, Thong SY, Chong YY, Ng SY. A review of perioperative anaphylaxis at a Singapore tertiary hospital. Sing Med J. 2016;57:126-31.

17. Bennet AT, Collins KA. An unusual case of anaphylaxis. Mold in pancake mix. Am J Forensic Med Pathol. 2001;22:292-5.

18. Brown SGA, Stone SF, FatovichDM BurrowsSA, Holdgate A, Celenza A, et al. Anaphylaxis: clinical patterns, mediator release, and severity. J Allergy Clin Immunol. 2013;132:1141-9.

19. Riches KJ, Byard RW. The detection of fatal anaphylaxis at autopsy-an overview. Scand J Forensic Sci. 2004;10:61-3.

20. Pumphrey RS, Roberts IS. Postmortem findings after fatal anaphylactic reactions. J Clin Pathol. 2000;53:273-6.

21. Herbst J, Heath K, Heddle R, Gilbert JD, Byard RW. Multiple bee stings, peritumoral mast cell degranulation and anaphylaxis-is there a relationship? J Forensic Leg Med. 2013;20:591-4.

22. Byard RW. Sudden death in the young. 3rd ed. Cambridge: Cambridge University Press; 2010. 